\title{
Blood glucose meter
}

National Diabetes Information Clearinghouse (NDIC)

\section{Definitions}

Diabetes

Defined by National Diabetes Information Clearinghouse (NDIC)

Blood glucose level

Defined by National Diabetes Information Clearinghouse (NDIC)

\section{Blood glucose}

Defined by National Diabetes Information Clearinghouse (NDIC)

\section{Source}

National Diabetes Information Clearinghouse (U.S.). (2009). The diabetes dictionary. [Bethesda, Md.]: U.S. Dept. of Health and Human Services, National Institutes of Health, National Institute of Diabetes and Digestive and Kidney Diseases, National Diabetes Information Clearinghouse.

A small, portable machine used by people with diabetes to check their blood glucose levels. After pricking the skin with a lancet, one places a drop of blood on a test strip in the machine. The meter then displays the blood glucose reading. 


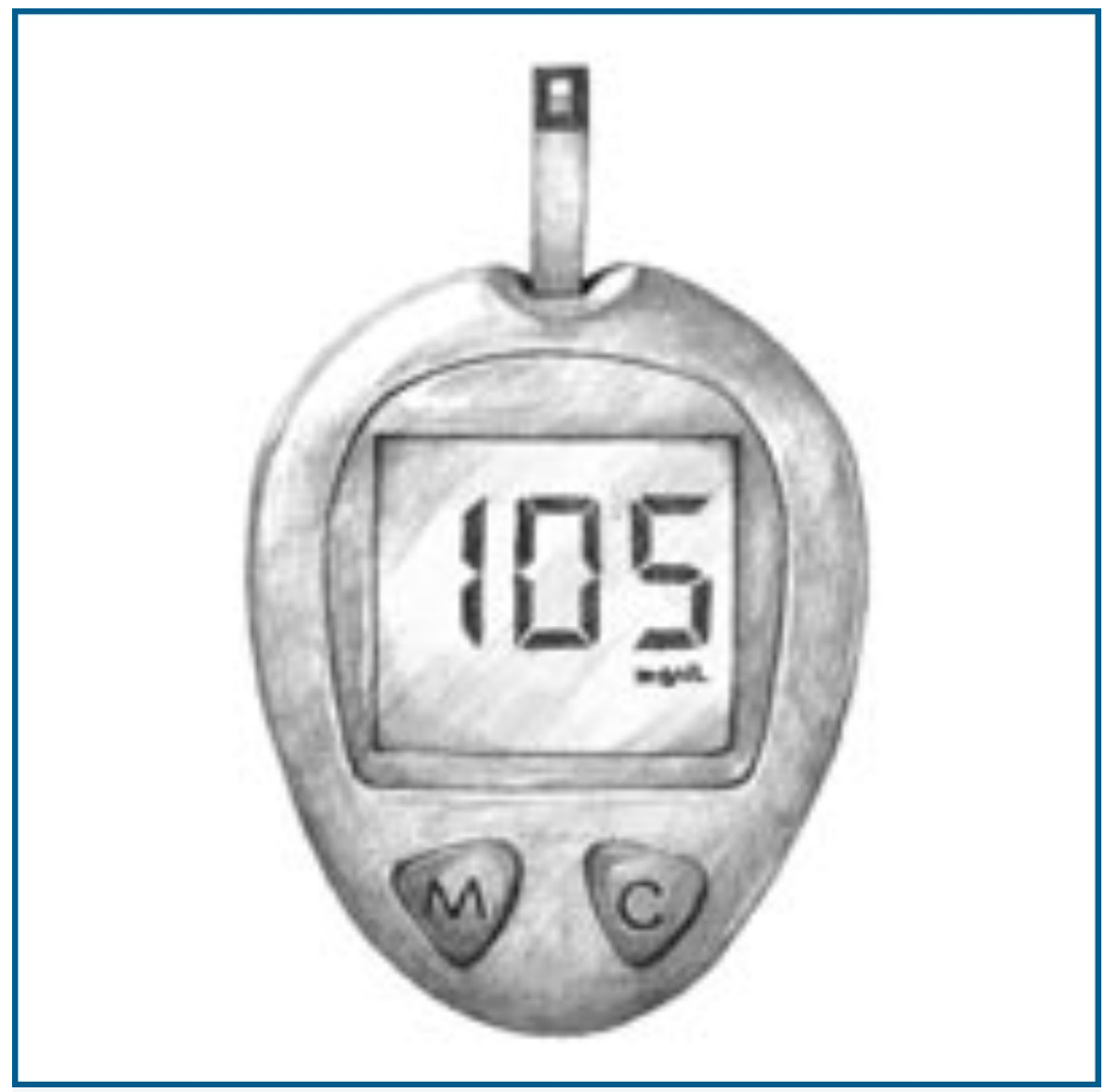

Blood glucose meter 